\title{
Analysis of 3D Planar Laminations in a Welded Section of API 5 L X52 Applying the Finite Element Method
}

\author{
Martin J. Fernández-Cueto ${ }^{1}$, Selene Capula-Colindres², Daniel Angeles-Herrera ${ }^{3}$, Julio C. Velázquez², \\ Gerardo Terán Méndez² \\ ${ }^{1}$ Instituto Tecnológico de Tuxtepec, Departamento de Metalmecánica, Tuxtepec Oax, México. \\ 2 Departamento de Ingeniería Química Industrial, ESIQIE, Instituto Politécnico Nacional, Zacatenco, México City, México. \\ ${ }^{3}$ Instituto Mexicano del Petróleo, Col. San Bartolo Atepehuacan, México.
}

Received: 08 Nov., 2017

Accepted: 03 Mar., 2018

E-mails: martinjfc@hotmail.com.mx (MJFC), selenecapula@gmail.com (SCC), dangelesh0600@alumno.ipn.mx (DAH), jcva8008@yahoo.com (JCV), gerardoteranm@gmail.com (GTM)
Abstract: The mechanical behavior of API $5 \mathrm{~L}$ X52 steel with planar type laminations was studied in the present work. Planar laminations were proposed in the base metal (BM), heat affected zone (HAZ) and welding bead (WB). Three-dimensional finite element (FE) models, kinematic hardening and mechanical properties for BM, HAZ, and WB were activated in the finite element program. The results showed that crack propagation corresponds to the direction of the main stress. For a crack length (2a) of $10.01 \mathrm{~mm}$, crack propagation may occur at the right crack tip towards the outer wall of the BM. For 2a of $15.12 \mathrm{~mm}$, crack propagation was located on the right crack tip and propagates to the inner wall. For 2a of $17.12 \mathrm{~mm}$, crack propagation was observed at the left crack tip and propagates to the outer wall in the BM. The results achieved by FEM agree when compared with real laminations in API $5 \mathrm{~L}$ pipelines.

Keywords: Planar laminations; API 5L X52 pipeline; Welded section; Finite element; Failure pressure.

\begin{tabular}{ccc}
\hline Nomenclature & \\
BM & base metal \\
FE & finite element \\
FEM & finite element method \\
H & atomic hydrogen \\
HAZ & heat affected zone \\
HIC & hydrogen induced cracking \\
$P_{\text {crack }}$ & internal pressure on the crack \\
$P_{f}$ & failure pressure \\
WB & welding bead \\
$\sigma_{\text {YS }}$ & yield stress \\
$\sigma_{\mathrm{UTS}}$ & ultimate tensile stress \\
$2 \mathrm{Ca}$ & crack length \\
\hline
\end{tabular}

This is an Open Access article distributed under the terms of the Creative Commons Attribution Non-Commercial License which permits unrestricted non-commercial use, distribution and reproduction in any medium provided the original work is properly cited.

\section{Introduction}

Pipelines are the safest and most reliable means of transportation for hydrocarbons. However, the anticorrosive system (cathodic protection and coating) can present problems or fail and the pipelines may be in contact with corrosive medium. This fact could motivate material degradation in any corrosion form, including cracking. The appearance of cracks makes the pipeline reliability decrease, causing the operational risk to increase [1].

It is widely recognized that cracking associated with an acidic environment is classified as hydrogen induced cracking ( $\mathrm{HIC}$ ) and plays an important role in the oil and natural gas industry [2,3]. Atomic hydrogen $(\mathrm{H})$ can diffuse through steel and penetrate into the metal. $H$ has various possible sources, such as a high-temperature, moist atmosphere, corrosion processes and electrolysis [4]. Therefore, it forms on the surface of the steel due to iron 
and $\mathrm{H}_{2} \mathrm{~S}$ corrosion reactions [5]. The $\mathrm{H}$ is absorbed on the inner surface of the wall of a steel pipeline and diffuses, see Figure 1. So, this hydrogen diffuses across the material and combines to form hydrogen molecules. It can be placed in defects; voids, holes, inclusions, impurities, dislocations or micro-cracks. Since molecular hydrogen cannot migrate from these defects [6], the pressure of hydrogen gas in the voids increases.

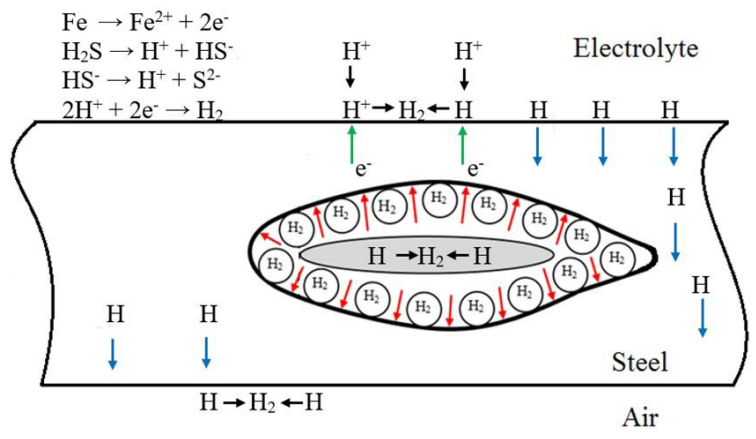

Figure 1. Schematic illustration of the mechanism for the lamination.

The mechanisms of HIC are closely related to the hydrogen diffusive process through metal. The driving force for the hydrogen diffusion in steel is mainly due to a gradient of hydrogen concentration, a state of non-uniform stress or a combination of both [7]. HIC is highly influenced by metallurgical parameters such as non-metallic inclusions, segregation bands of elements $(P, M n)$, grain boundaries, dislocations, microstructure, hardness, structural defects, and internal stresses. In addition, chemical parameters related to electrolytic media, such as $\mathrm{H}_{2}$ concentration, $\mathrm{pH}$, solution composition, exposure time, temperature, pressure and stresses applied. On the other hand, the surface finish has a significant influence on the diffusion process. Depending on the topographical characteristics of the surface, atomic hydrogen could be favored [8,9].

When the hydrogen molecule is placed in the defect, cracking is produced. HIC is characterized by stepped lamination or planar lamination. This cracking growth is in the same plane, parallel to the wall of the pipeline [10]. According to lino [11], a stress state in the vicinity of the crack tip is significantly influenced by the hoop external stress in API $5 \mathrm{~L}$ pipelines.

There are other sources of hydrogen that can be added to the metal, such as when the steel is in the refining stage. Hydrogen is incorporated with raw materials (scrap, lime, etc) in the form of water or through moisture in the air. It is highly harmful, causes cracking and brittleness in the steel, and lowers ductility in cold work. At this stage, the steel has low levels of $\mathrm{H}_{2}(\mathrm{~g})[12,13]$. Also, in pipeline manufacturing processes that require welding. In this process, the $\mathrm{H}_{2}$ can be added in the liquid state.

A lot of researchers have carefully studied the cracking speed [14] or the use of finite element method (FEM) to evaluate the mechanical behavior of several types of cracking for API 5L pipelines [15-27]. Those works are for the BM, while other works are focused on the hydrogen diffusion in pipelines [28-30], and HIC [31]. Unfortunately, at present, there are no work for planar laminations in the BM, HAZ, WB.

This paper attempts to obtain the mechanical resistance of an API $5 L$ X52 pipeline with planar laminations in the $B M, H A Z, W B$, with particular focus on the stresses fielded at the crack tips and crack propagation. Three-dimensional finite element models were applied using the FEM technique. Internal pressure was placed on the crack $\left(\mathrm{P}_{\text {crack }}\right)$ to generate yield stress $\left(\sigma_{\mathrm{YS}}\right)$, ultimate tension stress $\left(\sigma_{\mathrm{UTS}}\right)$ and failure pressure $\left(\mathrm{P}_{\mathrm{f}}\right)$. In addition, tension tests were conducted to obtain the stress-strain curves for the BM, HAZ and WB. To obtain the stress-strain curve of HAZ, the Vickers (HV) hardness profile was measured and applied to correlations between stresses and hardness.

\section{Materials and Methods}

\subsection{Mechanical properties for BM, HAZ, WB}

A sample specimen for the analysis (BM, HAZ, WB) is depicted in Figure 2 . It is noted that this specimen is only of example, since in this work a pipeline with a wall thickness of $25.4 \mathrm{~mm}$ was used. Tension and hardness Vickers (HV) tests were performed with the purpose of obtaining stress-strain curves for the zones of interest, such as BM, 
HAZ and WB. Standard specimens were machined following the ASTM E8-01 [32]. By doing this, tensile tests were carried out in a servohydraulic machine. The load was applied at a speed of $1.8 \mathrm{~mm} / \mathrm{min}$ according to ASTM E8. Three tension specimens were tested in each zone and the specimens were extracted in the longitudinal direction of the API 5L X52 with 609.6 mm outer diameter and $25.4 \mathrm{~mm}$ wall thickness. Figure 3 show the specimen's dimension.

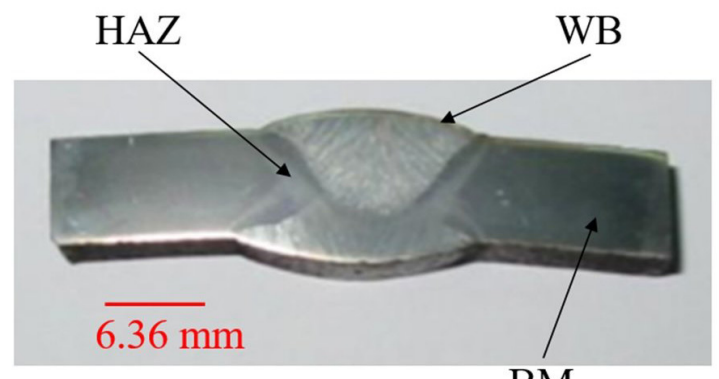

$\mathrm{BM}$

Figure 2. API 5L X52 pipeline, specimen extracted, heat affected zone (HAZ), weld bead (WB), and base metal (BM).

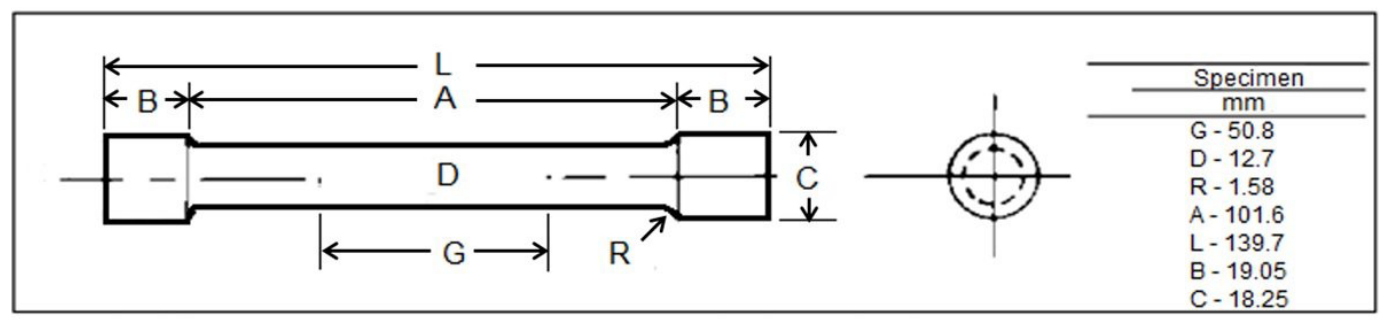

Figure 3. Specimen dimensions for the tension testing gage length (G), diameter (D), radius of fillet (R), width of grip section (C), length of reduced section (A), length of grip section (B), over-all length (L).

\subsection{Geometrical details}

In this section, it was considered the cracking that had developed in the BM and could propagate to the HAZ and WB without passing this last region (WB) [33]. It is well-known that high hydrogen pressure inside the crack is the main driving force for crack growth. Crack propagation of HIC in steel pipelines could occur in pipelines exposed to sulfurous compounds, such as hydrogen sulfite $\mathrm{H}_{2} \mathrm{~S}$ [31]. Based on this, Figure 4 presents a penny-shaped lamination model proposed for the present analysis.

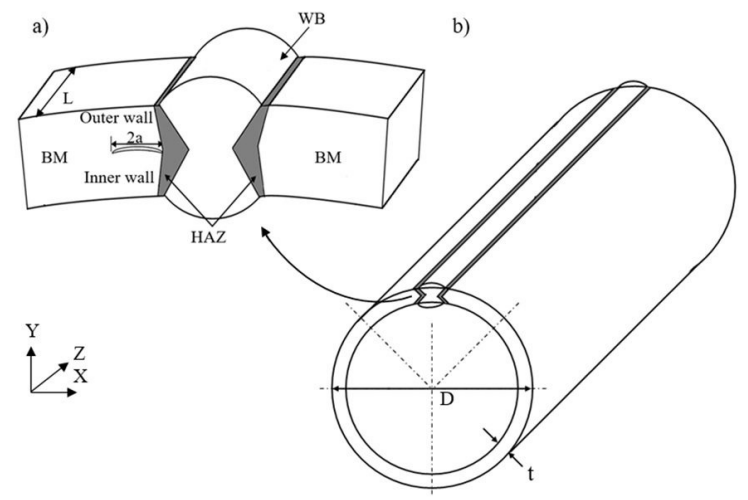

Figure 4. API 5L X52 pipeline: a) an embedded lamination at the mil-wall thickness, b) 3D FE model for the representation of planar lamination in the BM, HAZ, WB. 
Variables used in the numerical experimentation are presented in Table 1. The pipeline length (L) for all conditions were $76.2 \mathrm{~mm}$. It was proposed a crack that could start in the BM and propagate towards the HAZ, WB in a straigh extension. This initial crack was considered because it reached the form of a parallel crack towards the surface of the pipeline for a modeling profile during its formation by HIC. It was assumed that cracks produced by cathodic charging testing grow at a flat spread to approximately $50 \%$ of the wall thickness (2/t) [33]. Therefore, this value was defined to locate the crack in the wall thickness. The crack cut across the HAZ completely and propagated in the WB stopping halfway through this region [34]. Based on this, the largest extension for the crack length was defined (2a), $100 \%$ of the MB (10.01 mm) see Figure $5 a), 100 \%$ of the HAZ (15.12 mm) see Figure $5 b)$ and $50 \%$ of the WB $(17.24 \mathrm{~mm})$ see Figure $5 \mathrm{c})$.

Table 1. Variables used in the numerical experimentation.

\begin{tabular}{|c|c|c|c|c|c|c|}
\hline \multirow{3}{*}{ Conditions } & \multirow{2}{*}{ D } & \multirow{2}{*}{$\mathbf{t}$} & \multirow{3}{*}{$D / t$} & \multicolumn{3}{|c|}{ crack length, 2a } \\
\hline & & & & \multirow{2}{*}{$\begin{array}{c}\mathrm{MB} \\
\mathrm{mm}\end{array}$} & \multirow{2}{*}{$\frac{\mathrm{HAZ}}{\mathrm{mm}}$} & \multirow{2}{*}{$\begin{array}{c}\text { WB } \\
\mathrm{mm}\end{array}$} \\
\hline & $\mathbf{m m}$ & $\mathbf{m m}$ & & & & \\
\hline 1 & 609.6 & 12.7 & 48 & 10.01 & -- & -- \\
\hline 2 & 609.6 & 12.7 & 48 & 10.01 & 15.12 & -- \\
\hline 3 & 609.6 & 12.7 & 48 & 10.01 & 15.12 & 19.37 \\
\hline 4 & 609.6 & 9.525 & 64 & 10.01 & -- & -- \\
\hline 5 & 609.6 & 9.525 & 64 & 10.01 & 15.12 & -- \\
\hline 6 & 609.6 & 9.525 & 64 & 10.01 & 15.12 & 19.37 \\
\hline 7 & 609.6 & 6.35 & 96 & 10.01 & -- & -- \\
\hline 8 & 609.6 & 6.35 & 96 & 10.01 & 15.12 & -- \\
\hline 9 & 609.6 & 6.35 & 96 & 10.01 & 15.12 & 19.37 \\
\hline
\end{tabular}

$\mathrm{D}=$ diameter of pipeline; $\mathrm{t}=$ thickness .
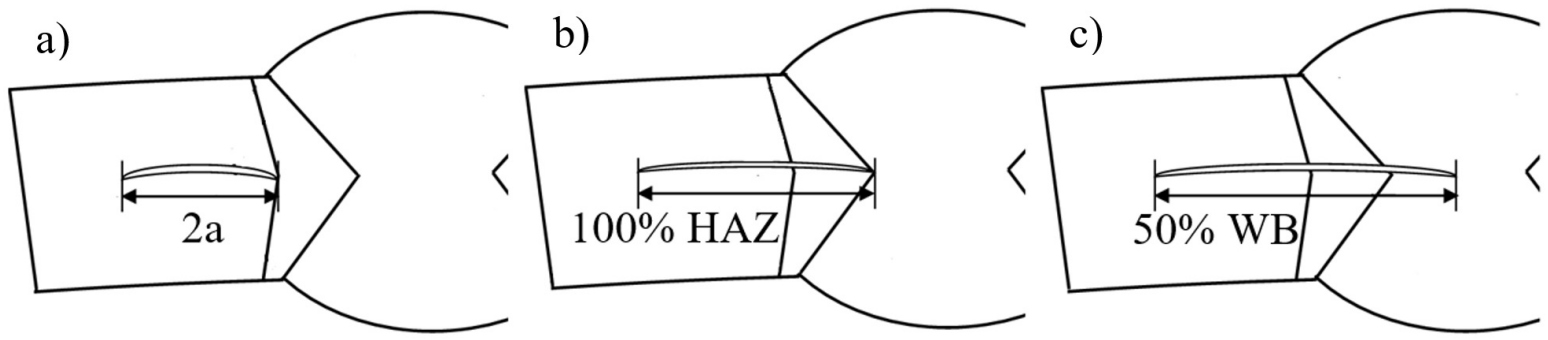

Figure 5. Planar lamination configurations for conditions using FE based on Table 3, a) 1, 4, 7, b) 2, 5, 8, and c) 3, 6, 9.

Yan, et al [21] found that hydrogen concentration in the HAZ is very high, and crack propagation could pass the HAZ completely. Thus, for the configurations considered here, the number of simulations was 9 . These experimental groups used a diameter and thickness of $609.6 \mathrm{~mm}$ and $6.35,9.525$ and $12.7 \mathrm{~mm}$, respectively, considering ratios of $D / t=96,64$, and 48 .

\subsection{FE models}

In Figure 6, typical FE meshing for a pipeline is illustrated. A finite finite element software [35] was used in this study. Since the main purpose of this paper was to study the mechanical resistance of pipelines with planar lamination for the model proposed, a high degree of mesh refinement at the crack tips was needed, and large elements for the rest of the pipeline were used. Alvaro, et al [20] found that the local stress and strain fields are strongly dependent on the mesh size. In this sense, second order elements (solid 95) and first order elements (solid 45) [36] were assigned to mesh the crack tips and the rest of the pipeline, respectively, see Figure 7. The angle of the elements at the crack tips was $18^{\circ}$. Madenci, et al [37] used angles of $15^{\circ}$ to mesh the crack tips using finite program. Chong et al. [19] proposed angles of $15^{\circ}-22.5^{\circ}$ to mesh canoe-shaped cracks. Yi et al. [22] employed angles 


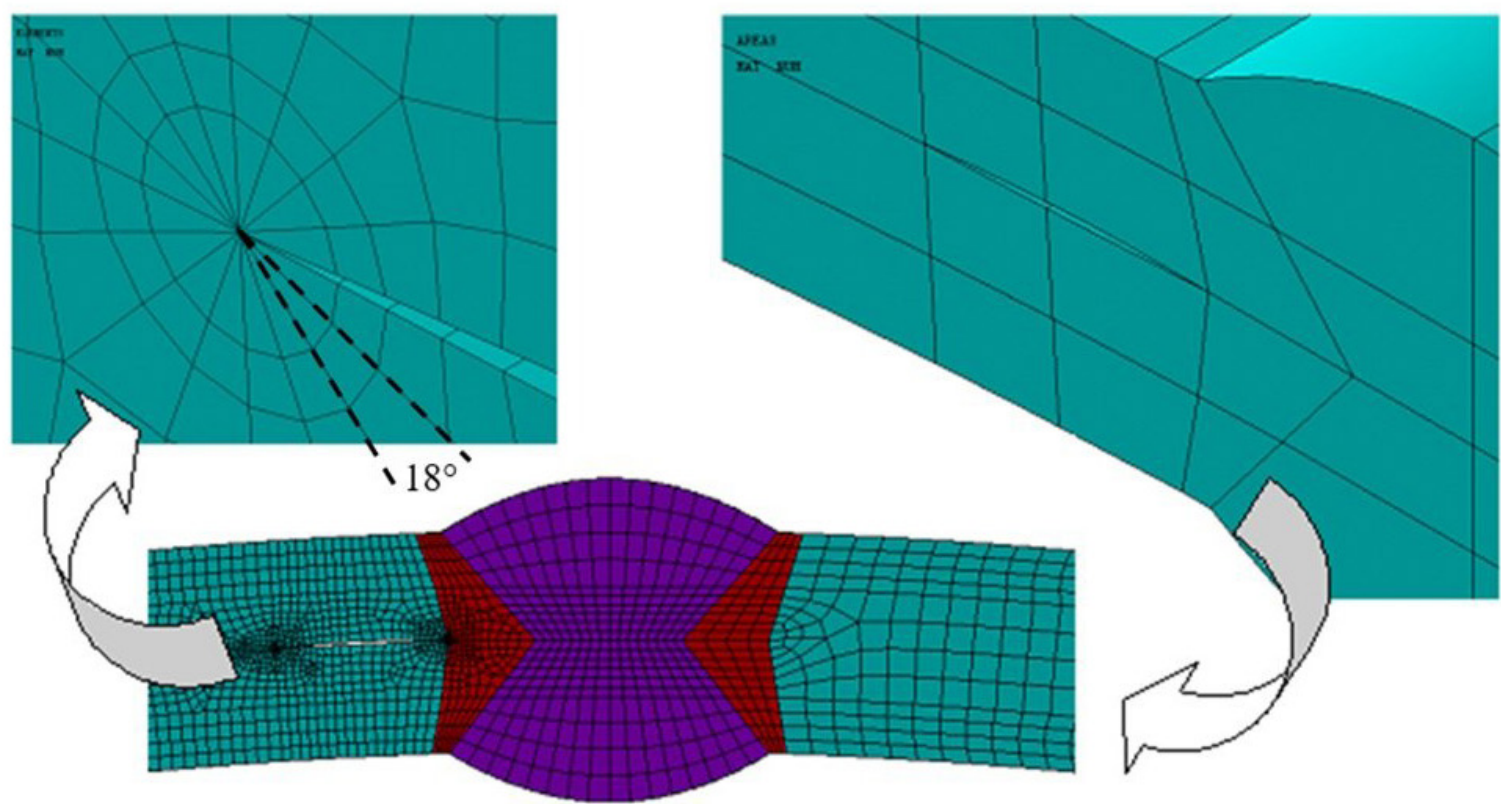

Figure 6. Typical FE meshing for pipeline with planar lamination.

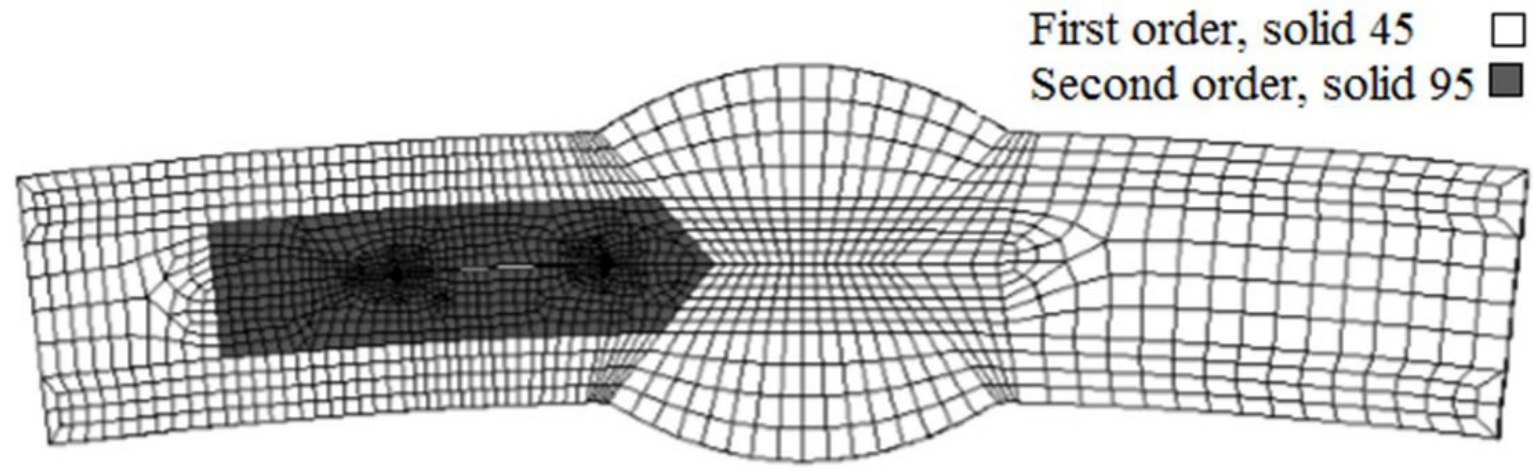

Figure 7. Isoparametric elements of first order (solid 45) and second order (solid 95).

of $18^{\circ}$ to mesh $3 \mathrm{D}$ cracking in pipelines. Plastic flow with isotropic hardening was activated in the finite element program to include non-linear analysis and simulate the material behavior for the BM, HAZ and WB.

Geometry modeling and FE generation were done in the rectangular coordinate system and then transferred to the cylindrical coordinate system to impose boundary conditions on the pipeline in the circumferential direction on the edge of the section. In this case, displacement by loads allowed free expansion of the pipeline, similar to what occurred in the real pipeline case. As illustrated in Figure 8a), axial boundary conditions were applied to the ends of the pipeline to simulate the continuity of a long pipeline. Pressure was applied to the inner surface of the crack until the $\sigma_{\mathrm{YS}}$ of the material was reached, see Figure $8 \mathrm{~b}$ ). When this value was reached, pressure was applied to the inner surface of the pipeline, until the $\sigma_{\mathrm{YS}}$ of the material was reached, see Figure 8c). This allowed the researchers to assess the load through pressure on a pipeline. Then, the pipeline was pressurized to achieve the $\sigma_{\mathrm{UTS}}$, and to define the operating range of the non-linear regime. The kinematic hardening rule was considered only to transfer the yield surface, plastically strain the material by increasing the stress until the $\sigma_{\mathrm{YS}}$ and $\sigma_{\mathrm{UTS}}$ of the material was reached [38]. This formulation was valid for representing a proper model for the real material [39], which is the situation considered in the present work. 
a)

b)
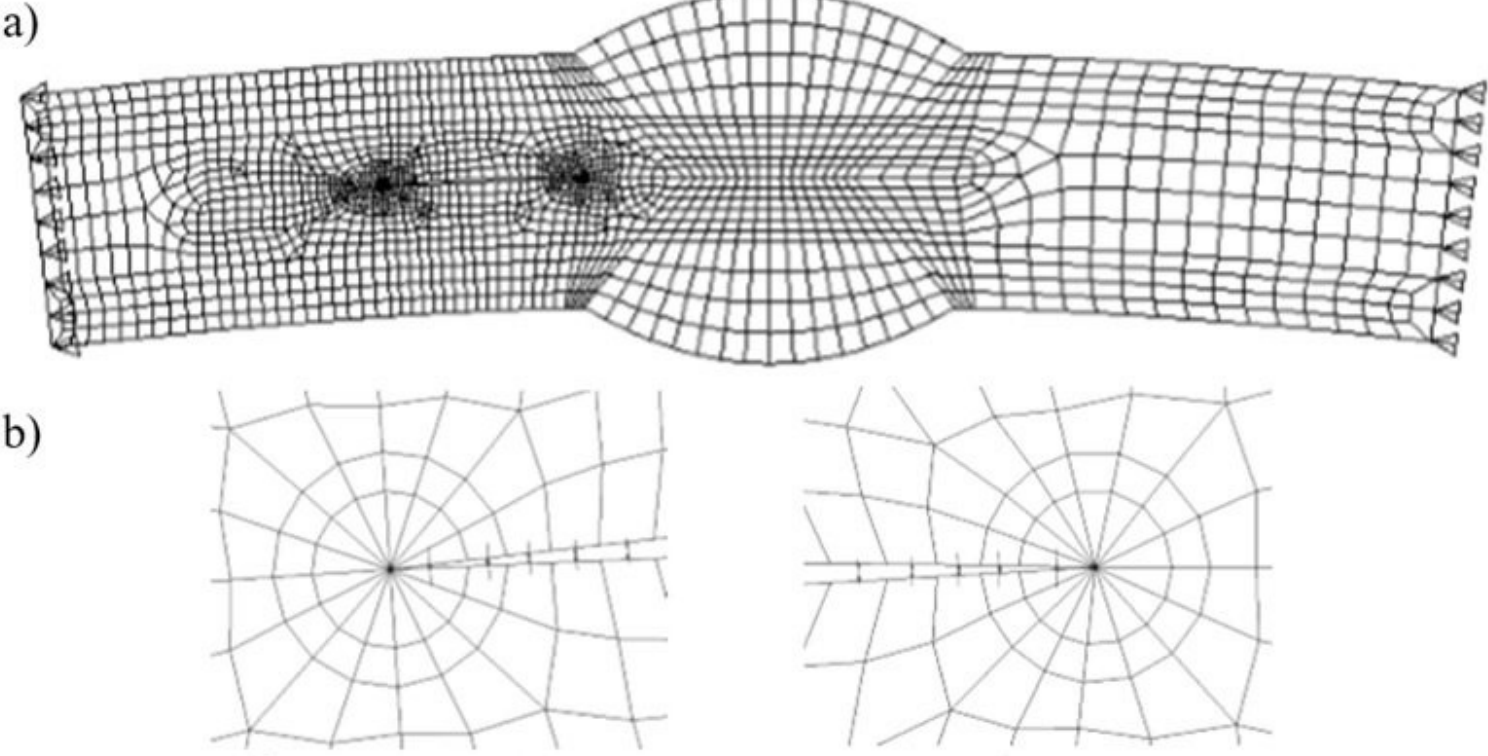

c)

\section{Left crack tip}

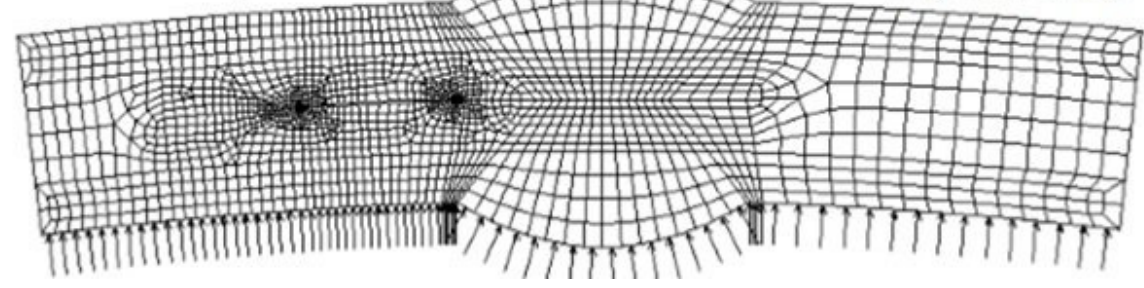

Figure 8. Typical loading and boundary conditions for the 3D finite element, a) boundary conditions, b) internal pressure for the crack, and c) internal pressure for the pipeline.

\section{Results}

\subsection{Mechanical properties results}

Table 2 summarizes the material properties for the three materials, BM, HAZ and WB. By using a relationship from this HV data, an equivalent true stress-strain curve in the HAZ was estimated. This data is depicted in Table 3, which presents the HV data. Hardness Vickers data was converted to stress-strain values by correlations with the corresponding hardness value obtained from the other two regions (BM and WB) and related to the stress-strain curves in order to obtain a curve proposed for the HAZ. Figure 9a) presents the engineering stress-strain curves and Figure 9b) shows the true stress-strain curves proposed.

Table 2. Mechanical properties for BM, HAZ and WB.

\begin{tabular}{ccccc}
\hline Zone & $\mathbf{E}(\mathbf{M P a})$ & $\boldsymbol{\sigma}_{\mathrm{Ys}}(\mathbf{M P a})$ & $\boldsymbol{\sigma}_{\text {UTs }}(\mathbf{M P a})$ & $\boldsymbol{\sigma}_{\mathbf{f}}(\mathbf{M P a})$ \\
BM-1 & 206,850 & 359.99 & 608.37 & 484.18 \\
BM-2 & 206,850 & 380.41 & 609.27 & 227.95 \\
BM-3 & 206,850 & 391.97 & 591.02 & 246.98 \\
HAZ & 206,850 & 363.01 & 616.20 & 489.60 \\
WB-1 & 206,850 & 383.01 & 628.26 & 505.63 \\
WB-2 & 206,850 & 385.83 & 601.15 & 520.96 \\
WB-3 & 206,850 & 367.46 & 161.85 & 495.87 \\
\hline
\end{tabular}

E, oYS, oUTS and of are modulus of elasticity, yield stress, ultimate tensile stress, and final stress, respectively. 
Table 3. Vickers hardness (HV) test results for the BM, HAZ, WB.

\begin{tabular}{ccccccc}
\hline & WB & WB & HAZ & BM \\
\hline BM & HAZ & 214.6 & 214.8 & 188.7 & 186.9 \\
186.4 & 189.1 & 214.4 & 214.5 & 188.9 & 186.7 \\
186.1 & 189.2 & 214.3 & 214.2 & 188.8 & 186.5 \\
\hline
\end{tabular}
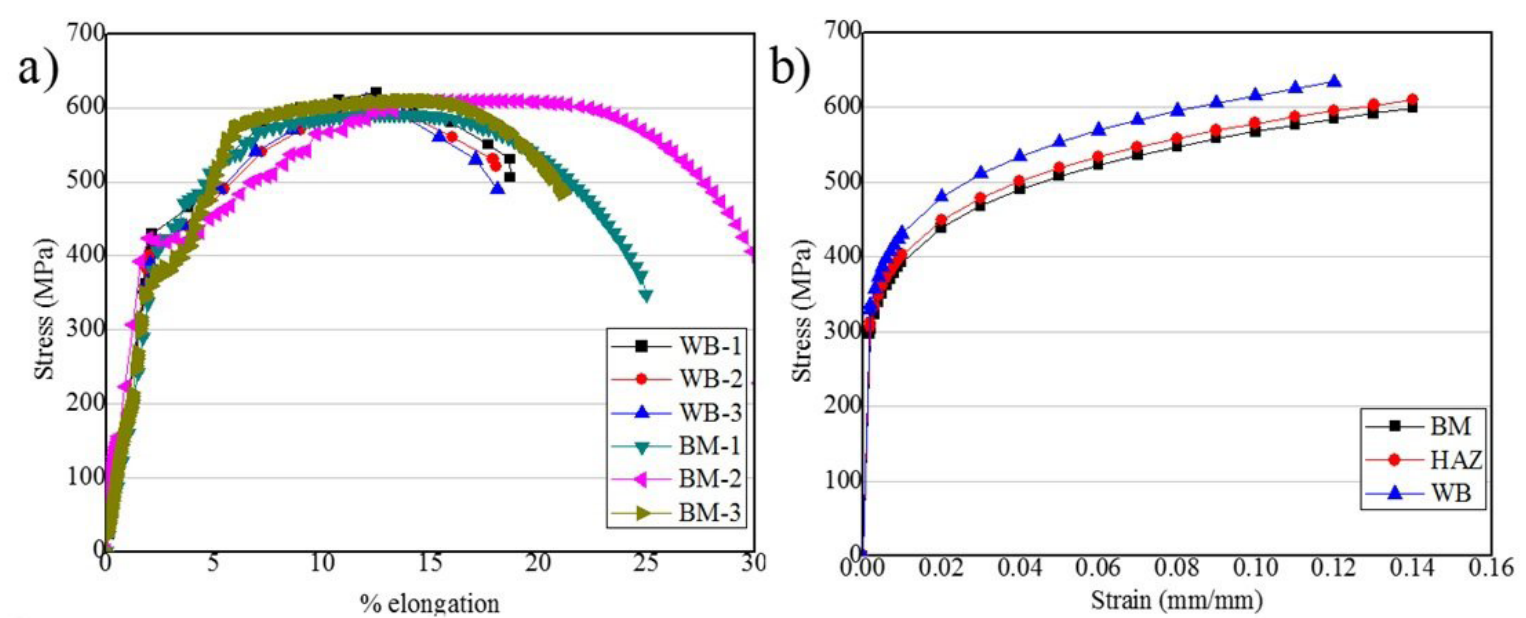

Figure 9. a) Engineering stress-strain curves and b) true stress-plastic curves extracted from API $5 \mathrm{~L}$ X52 steel. Base Metal (BM), Heat Affected Zone (HAZ), Welding Bead (WB).

\subsection{Pressure obtained by FEM}

Table 4 presents the pressures obtained by the FEM. The pressures recorded are: (i) pressure in the crack $\left(\mathrm{P}_{\text {crack }}\right)$ applied to generate the $\sigma_{\mathrm{YS}}$ (ii) pressure in the pipeline $\left(\mathrm{P}_{\mathrm{YS}}\right)$ applied to generate the $\sigma_{\mathrm{YS}}$ (iii) pressure in the pipeline $\left(\mathrm{P}_{\mathrm{UTS}}\right)$ applied to generate the $\sigma_{\mathrm{UTS}}$, and (iv) the pressure in the pipeline applied to generate the failure pressure $\left(P_{f}\right)$.

\section{Discussion}

\subsection{Presure data by FEM}

Plots of the pressure obtained by the FEM as a function of $2 a$ were made, see Figure 10 . The $P_{f}$ is defined as the pressure that makes the Von Mises stress in the outer and inner wall of the planar lamination reach or surpass the $\sigma_{\text {UTS }}$ of the material. These conditions indicate the failure of pipelines with planar lamination.

For three ratios $(D / t=48,64$ and 96$)$, it can be observed that the $P_{\text {crack }}$ pressure required in the crack to generate $\sigma_{Y S}$ in the material decreases as the $2 a$ increases, see Figure 10a). This trend was attributed to the fact that the crack size is greater. The cases of the $P_{Y S}, P_{U T S}$, and $P_{f}$, Figures 10b), c) and d), respectively, show an increased behavior of pressure as the pressure was increased to the $2 \mathrm{a}$. This behavior was attributed to the internal pressure related to the stress of the material. To reach high stress values, it was necessary to increase the pressure inside of the pipeline. 
Table 4. Pressures obtained by FEM in MPa.

\begin{tabular}{|c|c|c|c|}
\hline \multicolumn{4}{|c|}{ Pressure in the crack $\left(P_{\text {crack }}\right)$ to generate yield stress $\left(\sigma_{\mathrm{Ys}}\right)$. } \\
\hline \multirow{2}{*}{$2 \mathrm{a}, \mathrm{mm}$} & \multicolumn{3}{|c|}{$D / t$} \\
\hline & 48 & 64 & 96 \\
\hline 10.01 & 231.51 & 179.79 & 117.10 \\
\hline 15.12 & 149.19 & 113.6 & 72.18 \\
\hline 19.37 & 103.53 & 77.14 & 46.88 \\
\hline \multicolumn{4}{|c|}{ Pressure in the pipeline $\left(P_{\mathrm{YS}}\right)$ to generate yield stress $\left(\sigma_{\mathrm{YS}}\right)$. } \\
\hline \multirow{2}{*}{$2 a, \mathrm{~mm}$} & \multicolumn{3}{|c|}{$D / t$} \\
\hline & 48 & 64 & 96 \\
\hline 10.01 & 8.30 & 6.20 & 4.12 \\
\hline 15.12 & 10.84 & 7.43 & 3.94 \\
\hline 19.37 & 12.42 & 8.64 & 5.00 \\
\hline \multicolumn{4}{|c|}{ Pressure in the pipeline $\left(P_{U T S}\right)$ to generate ultimate tension stress $\left(\sigma_{U T S}\right)$. } \\
\hline \multirow{2}{*}{$2 a, \mathrm{~mm}$} & \multicolumn{3}{|c|}{$D / \mathbf{t}$} \\
\hline & 48 & 64 & 96 \\
\hline 10.01 & 14.37 & 11.38 & 8.22 \\
\hline 15.12 & 15.81 & 11.68 & 7.64 \\
\hline 19.37 & 16.69 & 17.74 & 7.79 \\
\hline \multicolumn{4}{|c|}{ Pressure in the pipeline to generate failure pressure $\left(P_{f}\right)$. } \\
\hline \multirow{2}{*}{$2 \mathrm{a}, \mathrm{mm}$} & \multicolumn{3}{|c|}{$\mathrm{D} / \mathrm{t}$} \\
\hline & 48 & 64 & 96 \\
\hline 10.01 & 18.81 & 14.45 & 10.35 \\
\hline 15.12 & 20.90 & 15.84 & 11.04 \\
\hline 19.37 & 22.00 & 16.73 & 11.39 \\
\hline
\end{tabular}
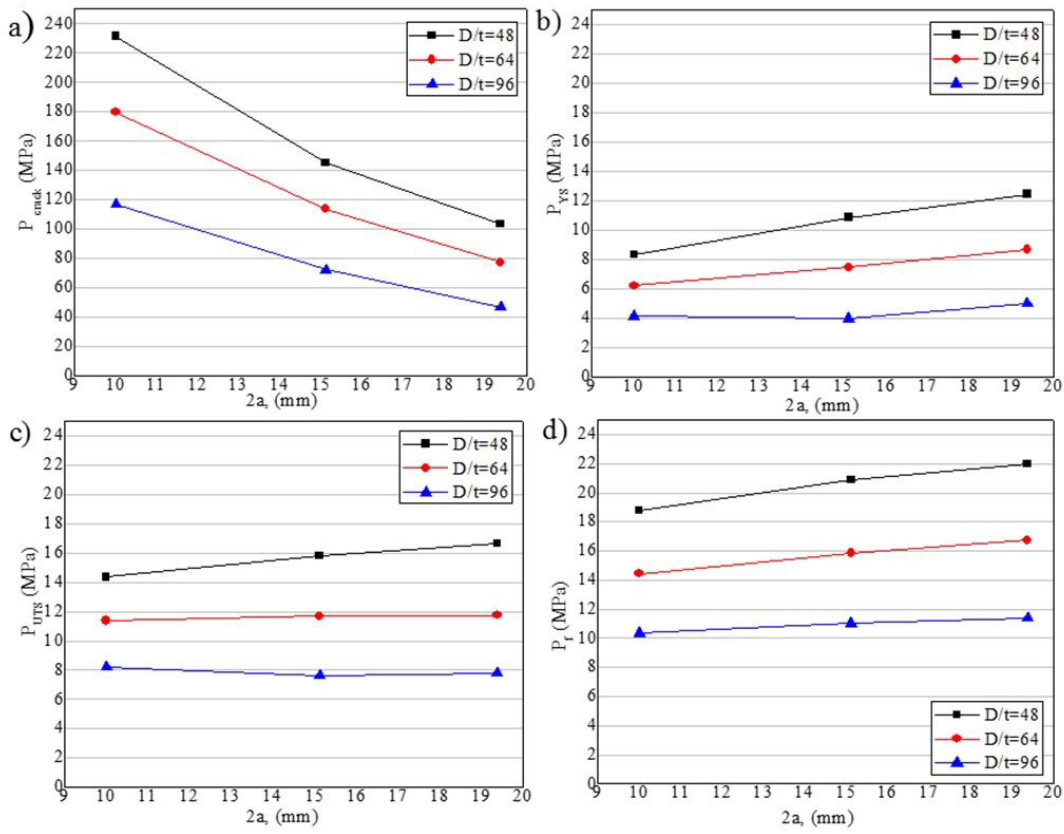

Figure 10. Plots of pressures obtained by FEM, a) $P_{\text {crack }}$, b) $\left.P_{Y S}, c\right) P_{U T S}$ and d) $P_{f}$. 
High hydrogen pressure inside a crack is the main driving force for crack growth. There are experimental works to simulate crack propagation in API 5L pipelines. Traidia, et al [31], employed pressure of $100 \mathrm{mbar}$ of $\mathrm{H}_{2} \mathrm{~S}$ for crack propagation. He found that the crack growth rate was mainly controlled by the material fracture toughness, crack location, $\mathrm{pH}$, and wall thickness of the pipelines. Kittel et al. [28] used the partial pressure of $\mathrm{H}_{2} \mathrm{~S}$ (3 mbar-1000 mbar] with different values of thickness $(0.5 \mathrm{~mm}-10 \mathrm{~mm})$. For simulation works, Servin et al. [16] used pressures of 46.4-264 MPa for 3D coplanar laminations in BM. He found that increasing the pressure in the lamination, the maximum stress at the crack tips spread out in a perpendicular direction, which is an indication of a probable growth in the crack. Morales et al. [17] used pressure values up to $1.72 \mathrm{MPa}$ and the load defects were pressured until total plastification in the lamination was reached. Gonzalez et al. [18] used pressure variations, 14-124 MPa, in coplanar laminations to achieve the maximum stress of the material (400 MPa) at the crack tips.

Kittel [28] and Traidia [31] reported pressures of $\mathrm{H}_{2} \mathrm{~S}$ from 100 mbar and 3-1000 mbar, respectively, for API X65 steel. These values should be considered for making comparisons of pressure in laminations. Even though they cannot be compared at present, since an API $5 \mathrm{~L} \mathrm{X52}$ is already being employed, it can be observed that the pressures are low. Pressure data reported by Servin [16], Morales [17] and Gonzalez [18] are high. These pressure values are used to obtain the maximum stress of the material at the crack tips. As shown in Figure 10a), for $2 \mathrm{a}$ of $10.01,15.12$ and $17.24 \mathrm{~mm}$, the pressures are 117.10, 72.1 and $46.88 \mathrm{MPa}$, respectively. It is noted that the ratio of $\mathrm{D} / \mathrm{t}=96(\mathrm{t}=6.35 \mathrm{~mm})$ is the lower thickness in the present study. As observed, this pressure of $\mathrm{H}_{2} \mathrm{~S}$ is low compared to the pressure obtained in the present work. It is necessary to mention that the pressures of $\mathrm{H}_{2} \mathrm{~S}$ are only for the crack propagation

\subsection{Analysis of planar laminations by FEM}

In the 3D FE model, the crack front fields are increasingly affected by the out of plane stress state based on the applied pressure levels [20]. The results of the simulations showed similar behavior according to the stress behavior for all pipelines. Only the analysis for the first condition was described, where a pipeline was considered with a $609.6 \mathrm{~mm}$ diameter, a wall thickness of $12.7 \mathrm{~mm}$, and a D/t $=48,2 \mathrm{a}$ of $10.01 \mathrm{~mm}$ in BM. Figure $11 \mathrm{a}$ ) shows Von Mises stresses distribution with the $\mathrm{P}_{\text {crack }}$ of $231.51 \mathrm{MPa}$. This figure shows that greater stresses are located at the vicinity of the crack tips. In this case, the outer and inner walls in the middle of the crack presented stresses higher than $\sigma_{\mathrm{YS}}$ of the material (376 MPa). These zones and the the tips of the cracks are affected. For three $\mathrm{D} / \mathrm{t}$ conditions analyzed where the pressure is constant in the $P_{\text {crack }}$ the stresses showed a tendency to be distributed across the wall thickness. In these zones, it was reaching a stress value of $\sigma_{U T S}$. A typical example of $\sigma_{U T S}$ is shown in Figure 11b). The mode of the main stress at the crack tips corresponds to the field stress of the plastic zone for mode I, which agree with the model proposed by Ikeda [15].

Wall thickness in the radial direction, combined with the effect of the hoop stresses produced by internal pressure in the pipeline, caused the stresses produced near the crack tips to be distributed across the wall thickness. To achieve the maximum strength value, the outer walls are plastified, which causes the failure by plastic collapse to become real. Vigdis $[29,30]$ assumed that failure occurs as soon as the first cohesive element at the crack tips

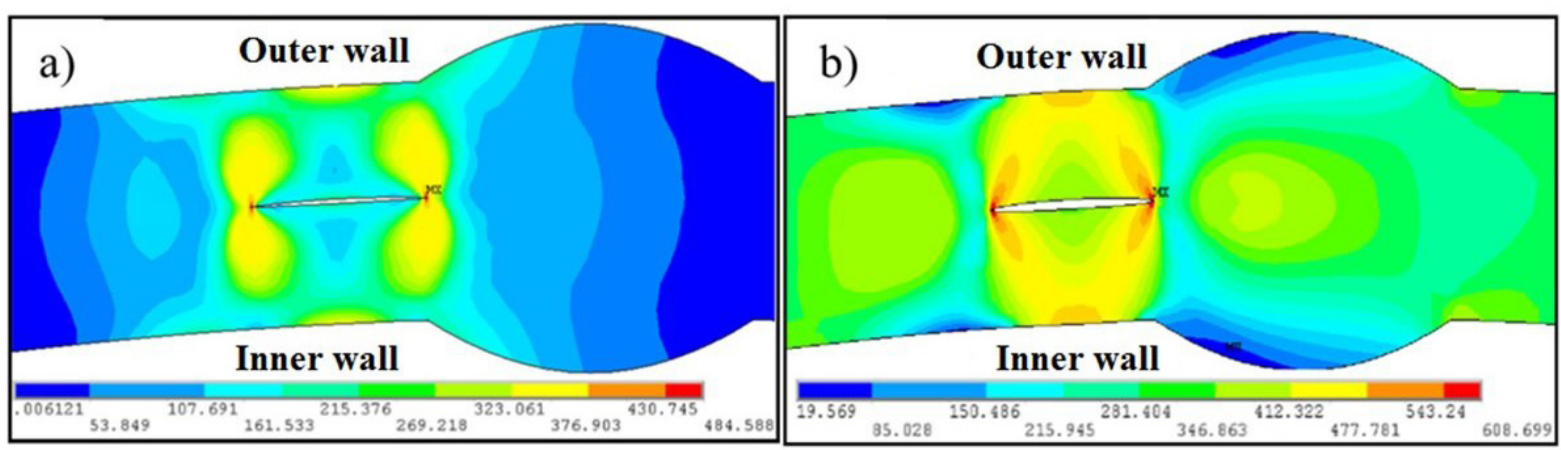

Figure 11. Typical view of the Von Mises stress for pipeline with planar lamination in BM, a) $P_{\text {crack }}$ and b) $P_{\text {UTS }}$ units in $\mathrm{MPa}$. 
has reached complete separation in the 3D FE simulations for the pipeline. When the maximum stress has been reached to separate the first element of the crack tip, crack propagation is carried out toward the areas where the wall thickness is weakest. As can be seen from Figure 11, maximum stresses are located at the crack tips. It indicates the stresses interacting at this region, which align with the development of cracking due to the interconnection of perpendicular cracks [11]. The above situation agrees with the fracture mechanics postulate, the direction of cracking corresponds to the direction of the main stresses.

Figure 12-14 shows the Von Mises stress causing failure in the pipeline for all conditions in the present work. It was observed in this figure that, for all work conditions, the stress distribution is higher at the crack tips in the part of the zone cracking (outer and inner wall), with certain stress variants at the BM and WB.

By using the Von Mises stress for the failure pressures, the failure of pipelines with planar lamination in the MB, HAZ, WB could be predicted by FE. For example, for $2 a$ of $10.01 \mathrm{~mm}$ and ratios of $D / t=48,64$ and 96 , crack propagation may occur at the right crack tip towards the outer wall of the BM. For $2 a$ of $15.12 \mathrm{~mm}$ and ratios of $\mathrm{D} / \mathrm{t}=48,64$ and 96 , crack propagation is located on the right crack tip and propagates to the inner wall. Finally, for $2 a$ of $17.12 \mathrm{~mm}$ and ratios of $\mathrm{D} / \mathrm{t}=48,64$ and 96 , crack propagation is observed at the left crack tip and propagates to the outer wall in the BM. Everything described above is depicted in Figure 15-17. This behavior was attributed to the fact that this zone presented a greater amount of material. Indeed, WB presents high strength values in the stress-strain curve compared with HAZ and BM. Therefore, these high stress values of WB make the crack propagation occur at the BM. Morales, et al [17] found that the maximum stress is located in the outer wall of the

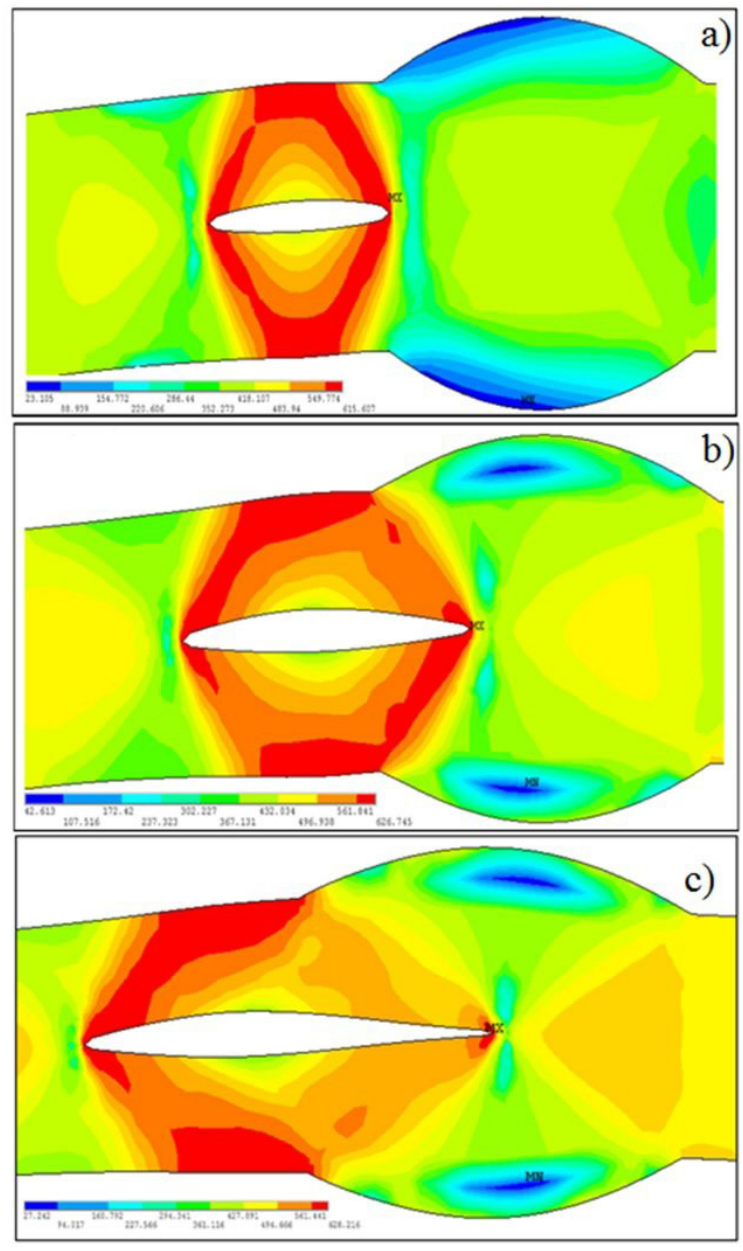

Figure 12. Von Mises stress for failure pressure in a pipeline with planar laminations with $D / t$ of 48 ; a) $2 a$ of $10.01 \mathrm{~mm}$, b) 2a of $15.12 \mathrm{~mm}$ and c) 2a of $17.12 \mathrm{~mm}$, units in MPa. 


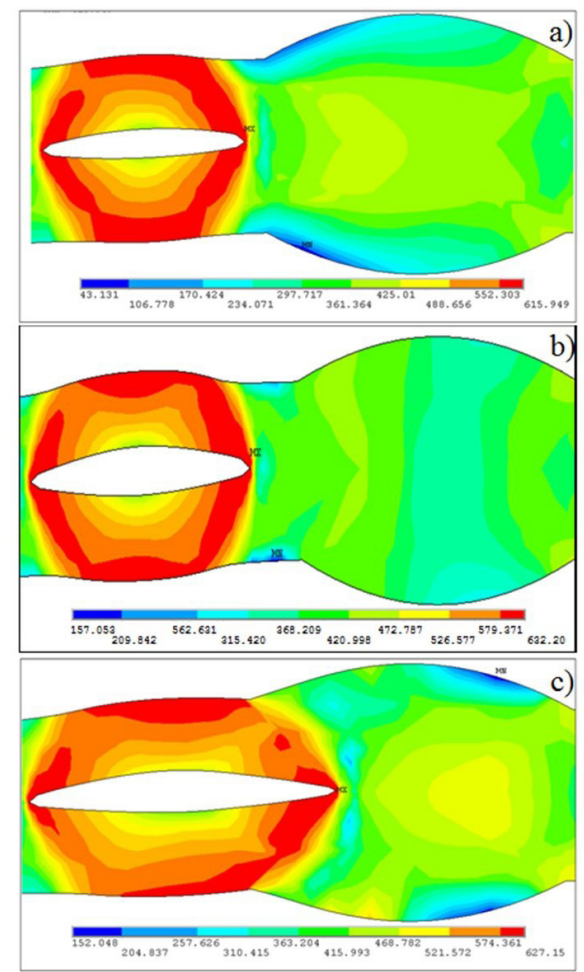

Figure 13. Von Mises stress for failure pressure in a pipeline with planar laminations with $D / t$ of 64 ; a) 2a of $10.01 \mathrm{~mm}, \mathrm{~b}) 2 \mathrm{a}$ of $15.12 \mathrm{~mm}$ and c) 2a of $17.12 \mathrm{~mm}$, units in MPa.

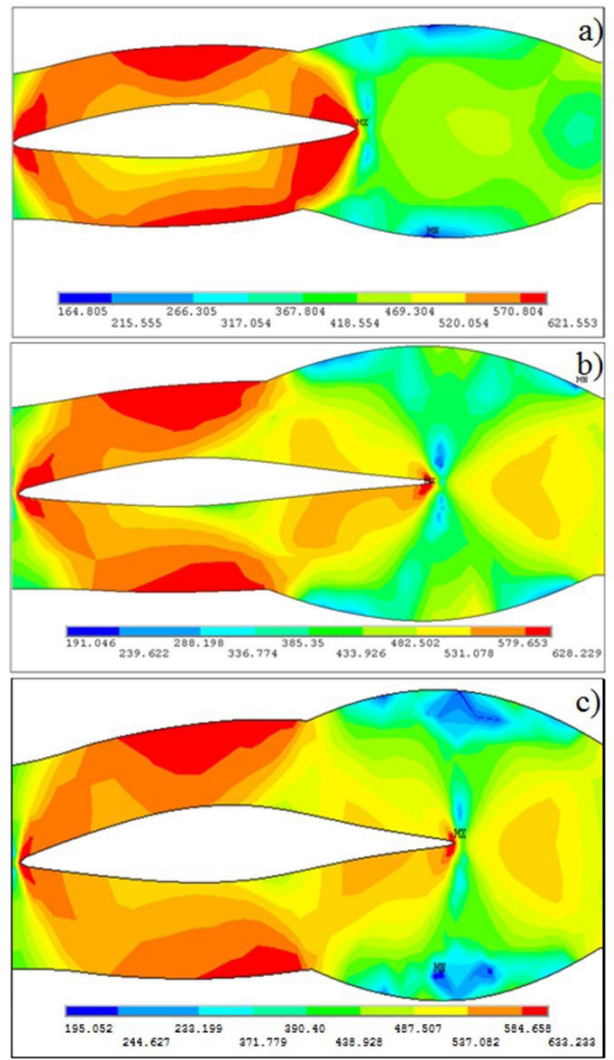

Figure 14. Von Mises stress for failure pressure in a pipeline with planar laminations with $D / t$ of 96 ; a) 2a of $10.01 \mathrm{~mm}$, b) 2a of $15.12 \mathrm{~mm}$ and c) 2a of $17.12 \mathrm{~mm}$, units in MPa. 

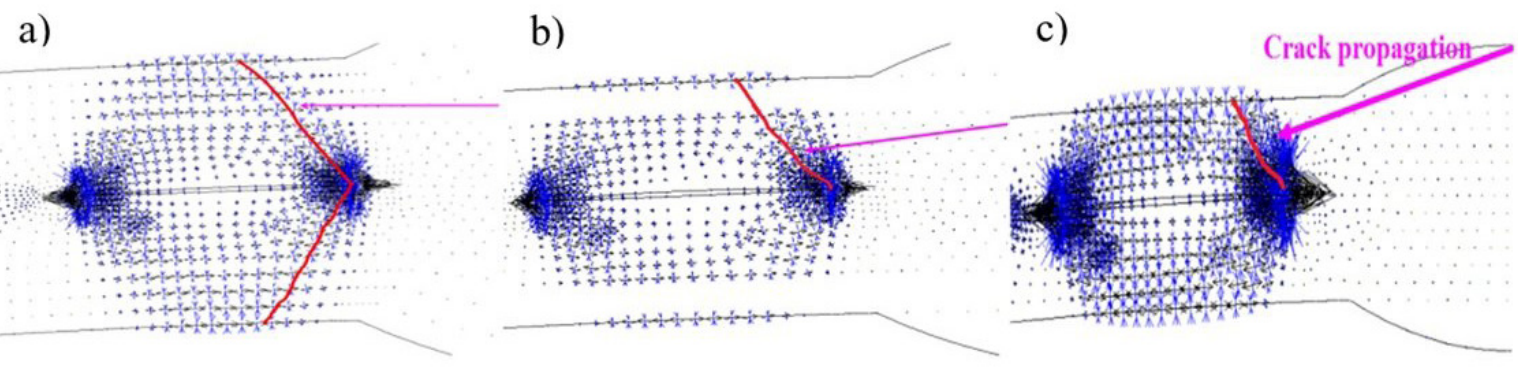

Figure 15. Direction proposed for the crack propagation in pipelines with planar laminations with D/t of 48 ; a) $2 \mathrm{a}$ of $10.01 \mathrm{~mm}$, b) $2 a$ of $15.12 \mathrm{~mm}$ and c) $2 a$ of $17.12 \mathrm{~mm}$.
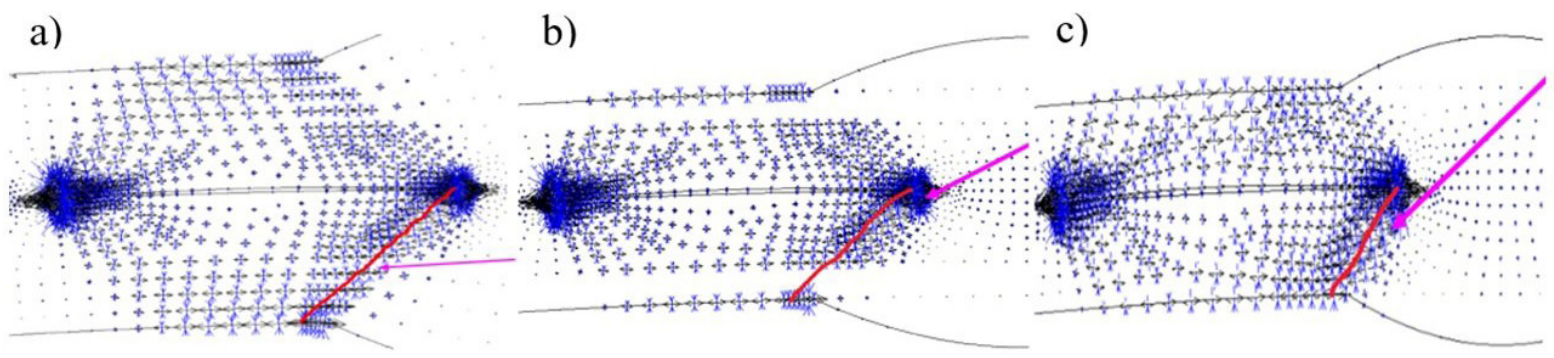

Figure 16. Direction proposed for the crack propagation in pipelines with planar laminations with D/t of 64 ; a) 2a of $10.01 \mathrm{~mm}$, b) $2 a$ of $15.12 \mathrm{~mm}$ and c) $2 a$ of $17.12 \mathrm{~mm}$.

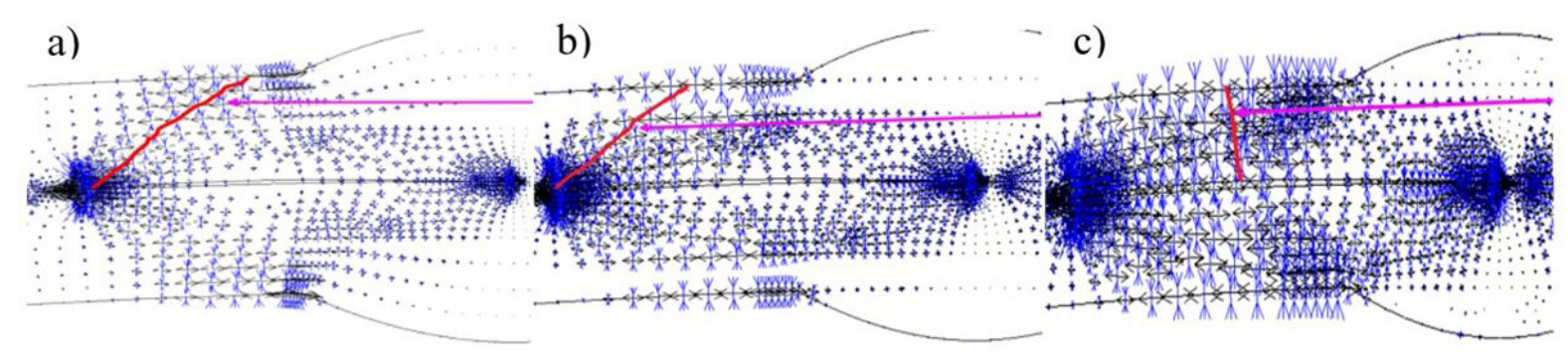

Figure 17. Direction proposed for the crack propagation in pipelines with planar laminations with D/t of 96 ; a) 2a of $10.01 \mathrm{~mm}, \mathrm{~b}) 2 \mathrm{a}$ of $15.12 \mathrm{~mm}$ and c) 2a of $17.12 \mathrm{~mm}$.

lamination, and the failure could be expected here. Consequently, these factors make the crack propagation occur at either the right or left crack tip and propagate on the outer or inner wall of the BM.

As shown in section 3.1 and the information described above by FE, pressure obtained (given in references by [28-30]) at the cracks' tips is too low when compared to the works reported by FE [16-18]. This supposes that the pipelines with laminations could not fail by the pressure generated by experimental hydrogen diffusion. Those pipelines fail when the Von Mises stresses reach or surpass the $\sigma_{U T S}$ in the lamination zone due to internal pressure. Additionally, the lamination size is large in this study. These two factors make the pipelines unable to support the internal pressures applied by FE, and the failure is located in the outer and inner wall of the lamination at the BM. In this context, pipelines with laminations could not fail at the HAZ or WB. This is confirmed, making a comparison of the results obtained by FEM when it was compared with an image of API $5 \mathrm{~L}$ pipeline that presents step-wise cracking. It is noted that crack propagation at the left crack tip is toward the outer wall of the pipeline, see Figure 18. Although this image is for stepped lamination, and the work is for planar lamination, it confirms that the crack propagation follows the main stresses towards the top left zone. 


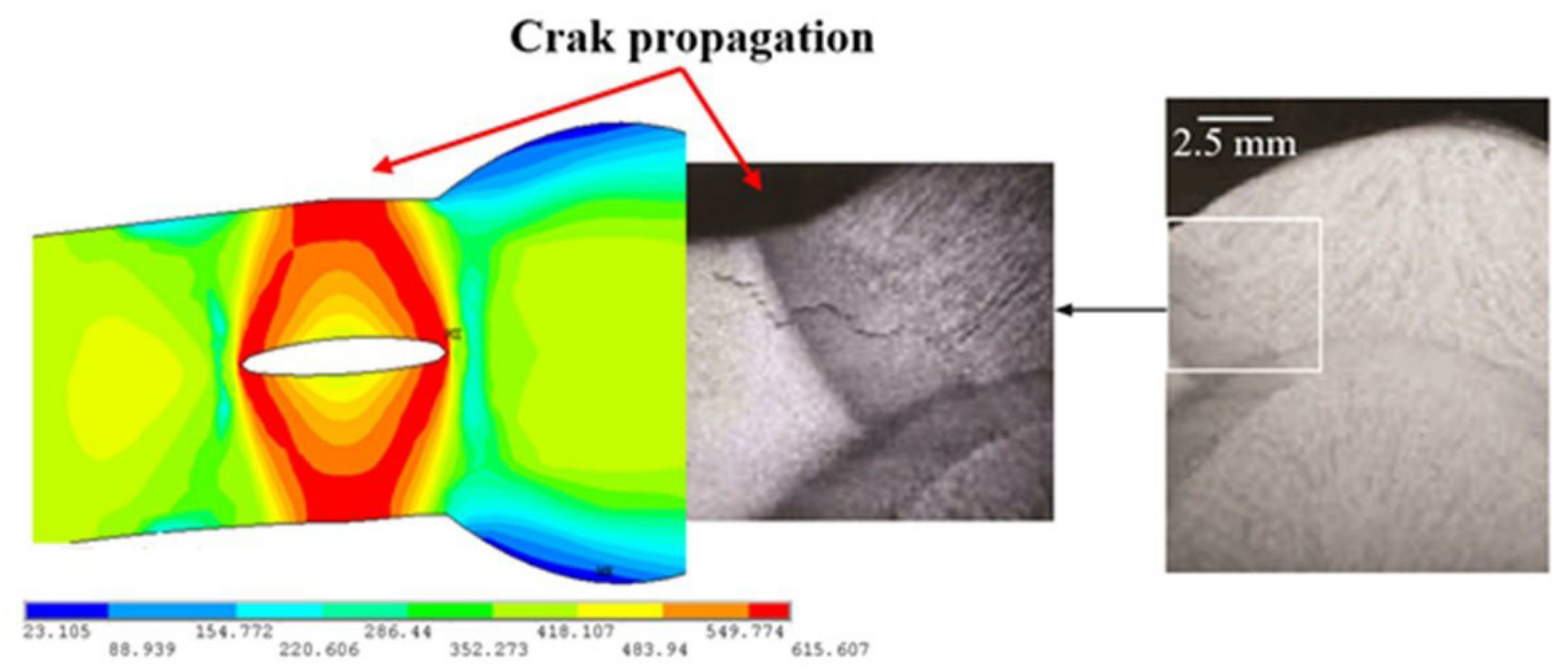

Figure 18. Crack propagation in pipelines with laminations towards the BM, units in MPa.

The industry-wide standard that is responsible for making assessments in vessel pressure is the API 579-1/ASME FFS-1 Fitness-for-service, Part 7 - Assessment of hydrogen blisters and hydrogen damage associated with HIC and stress oriented HIC (SOHIC), Part 9 assessment of crack-like flaws, and Part 13 assessmen of laminations [40]. For Part 7 , the HIC for the three levels of evaluation is taken as a reference. The level 1 assessment procedure provides screening criteria to evaluate HIC damage, considering the damage from the perspective of local metal loss. While the level 2 assessment procedure utilizes the methodologies of Part 5 and Part 9 to evaluate the damage zone as a region of local metal loss and as a crack, respectively. The level 3 assessment of HIC damage may be performed using FE analysis considering explicit modeling of HIC damaged and non-damaged areas. Limit load or elastic plastic analysis may be performed. The HIC damaged areas must be modeled as elastic-perfectly plastic material. All parameters above at the part 7 level 3 are used in the present work. While in part 9 assessment, levels 1 and 2 are very conservative, and it is neccesary to make assessments for level 3, where advanced stress analysis techniques are required to define the state of the stress at the location of the flaw because of complicated geometry and/or loading conditions. Otherwise, numerical analysis techniques such as the FEM could be used to determine the stress field at the crack location. It is recommended that the crack-like flaw in the component may be computed using elastic-plastic analysis by FE. Finally, for Part 13 assessment, laminations that originated from $\mathrm{HIC}$ or SOHIC are not considered. This part considers that the laminations are planes of non-fusion in the interior of a steel plate that are a result of the steel manufacturing process.

\section{Conclusions}

Cracking by HIC in BM, HAZ or WB is one of the main failure for the pipelines that transport hydrocarbons. The standard that provides assessment for the failure analysis of cracking and HIC is the API 579-1/ASME FFS-1 "Fitness-for-service". This standard shows different assessment levels and it does not consider cracking in the heat affected zone or WB. It only considered cracking in the base metal. Then, it is important to study by FEM the mechanical behavior in 3D laminations to determine the crack propagation and the pipe failure pressure. Crack propagation follows the direction of the main stress. So, failure in a pipeline with planar lamination could be predicted by finite element modeling. For a size (2a) of $10.01 \mathrm{~mm}$ and ratios of $\mathrm{D} / \mathrm{t}=48,64$ and 96 , crack propagation may occur at the right crack tip towards the outer wall of the BM. For size (2a) of $15.12 \mathrm{~mm}$ and ratios of $D / t=48,64$ and 96 , crack propagation is located on the right crack tip and propagates towards the inner wall and the stress concentration zone. Finally, for size (2a) of $17.12 \mathrm{~mm}$ and ratios of $\mathrm{D} / \mathrm{t}=48,64$ and 96 , crack propagation is observed at the left crack tip and propagates to the outer wall in the BM.

Pipelines with planar laminations fail because Von Mises stresses reach or exceed the $\sigma_{\text {UTS }}$ in the lamination zone due to internal pressure and critical lamination size. Pipelines cannot support the internal pressure, and the failure is expected at the outer wall because of coplanar laminations for BM. Failure in pipelines with coplanar 
laminations could only be presented in the BM zone. However, for the HAZ and WB, failure is not expected. The results obtained by FEM agree with real laminations in API $5 \mathrm{~L}$ pipelines where the crack propagation is at the left crack tip and propagates towards the outer wall.

\section{Acknowledgements}

The authors thank ITT, Intituto Politécnico Nacional, ESIQIE, IMP and CONACYT, for the financial and material support.

\section{References}

[1] Caleyo F, Valor A, Venegas V, Espina-Hernandez JH, Velazquez $J C$, Hallen JM. Pipeline Integrity-1: accurate corrosion modeling improves reliability estimations. Oil \& Gas Journal. 2012;110:122128.

[2] Still J.R. 2004. Understanding hydrogen failures of ferritic welds. Welding Journal. 82(1):26-29.

[3] Ossai Cl, Boswell B, Davies IJ. Pipeline failures in corrosive enviroments - a conceptual analysis of trend and effects. Engineering Failure Analysis. 2015;53:36-58. http://dx.doi. org/10.1016/j.engfailanal.2015.03.004.

[4] Fontana MG. Corrosion engineering. New York: McGraw Hill; 1987.

[5] Liou HY, Shieh RI, Wei FI, Wang SC. Roles of microalloying elements in hydrogen induced cracking resistant property of HSLA Steels. Corrosion. 1993;49(5):389-398. http://dx.doi. org/10.5006/1.3316066.

[6] Ravi K, Ramaswamy V, Namboodhiri TKG. Hydrogen sulphide resistance of high sulphur microalloyed steels. Materials Science and Engineering A. 1990;129(1):87-97. http://dx.doi. org/10.1016/0921-5093(90)90347-6.

[7] Romero M.F., Duque Z., Rincón O.T., Pérez O. \& Araujo I. 2003. Estudio de la teoría de despolarización catódica con permeación de hidrógeno y la bacteria Desulfovibrio desulfuricans. Revista de Metalurgia. 39(1):182-187. http://dx.doi.org/10.3989/ revmetalm.2003.v39.iExtra.1117.

[8] Requiz R, Vera N, CameroS. Influencia del acabado superficial en la permeaciòn de hidrógeno del acero API $5 \mathrm{~L}$ X52. Revista de Metalurgia. 2004;40(1):30-38. http://dx.doi.org/10.3989/ revmetalm.2004.v40.i1.240.

[9] Carreño J.A., Uribe I. \& Carrillo J.C. 2003. Modelado del efecto de rugosidad en la permeación de hidrógeno en un acero de bajo carbono. Revista de Metalurgia. 39(1):213-218.

[10] Gonzalez JL, Ramirez R, Hallen JM, Guzman RA. Hydrogeninduced crack growth rate in steel plates exposed to sour environments. Corrosion. 1997;53(12):935-943. http://dx.doi. org/10.5006/1.3290278.

[11] lino M. The extension of hydrogen blister-crack array in linepipe steels. Metallurgical Transactions. A, Physical Metallurgy and Materials Science. 1978;9a(11):1581-1590. http://dx.doi. org/10.1007/BF02661940.

[12] Maarten G, Hisko T, Corvan DV. Modern blast furnace ironmaking: an introduction. 2nd ed. Netherlands: Delf University Press; 2009.

[13] Ahindra G, Amit C. Iron making and steelmaking: theory and practice. India: PHI Learning; 2008.

[14] Ramirez JA. Susceptibilidad al agrietamiento inducido por hidrógeno absorbido, de la soldadura y zona afectada por el calor, en aceros para transporte de hidrocarburos [master degree thesis]. México DF: ESIQIE-IPN; 2003.
[15] Ikeda A, Morita Y, Terasaki F, Takeyama M. On the hydrogen induced cracking of line-pipe steel under wet hydrogen sulfide environment. Proceedings of The 2 nd International Congress on Hydrogen in Metals; 1997 June 6-11; Paris. France; 1977. p. 1-8.

[16] Alberto S, Gonzalez JL, Morales A. Behavior of coplanar and non-coplanar laminations in API5L X52 simulated by finite elements. Información Tecnológica. 2009;20(5):97-105.

[17] Morales A, Gonzalez JL, Hallen JM. Mechanical behavior of non-coplanar cracks in pipes applying the finite elements method. Información Tecnológica. 2004;15(6):29-34.

[18] Gonzalez JL, Morales A. Analysis of laminations in X52 steel pipes by nonlinear by finite element. International Journal of Pressure Vessel and Technology. 2008;130(2):021706. http:// dx.doi.org/10.1115/1.2894295.

[19] Chong TS, Kumar SB, Lai M, Loh WL. Fracture capacity of morden pipeline girth welds with 3D surface cracks under extreme operation conditions. Engineering Fracture Mechanics. 2015;146:139-160. http://dx.doi.org/10.1016/j.engfracmech.2015.07.032.

[20] Alvaro A, Olden V, Akselsen OM. 3D cohesive modelling of hydrogen embrittlement in the heat affected zone of an X70 pipeline steel. International Journal of Hydrogen Energy. 2013;38(18):75397549. http://dx.doi.org/10.1016/j.ijhydene.2013.02.146.

[21] Yan C, Liu C, Yan B. 3D modeling of the hydrogen distribution in X80 pipeline steel welded joints. Computational Materials Science. 2014;83:158-163. http://dx.doi.org/10.1016/j. commatsci.2013.11.007.

[22] Yi D, Xiao ZM, Idapalapati S, Kumar SB. Fracture analysis of girth welded pipelines with 3D embedded cracks subjected to biaxial loading conditions. Engineering Fracture Mechanics. 2012;96:570587. http://dx.doi.org/10.1016/j.engfracmech.2012.09.005.

[23] Ruggieri C, Dotta F. Numerical modeling of ductile crack extension in high pressure piplines with longitudinal flaws. Engineering Structures. 2011;33(5):1423-1438. http://dx.doi.org/10.1016/j. engstruct.2011.01.001.

[24] Nourpanah N, Taheri F. Ductile crack growth and constrain in pipeline subject to combined loading. Engineering Fracture Mechanics. 2011;78(9):2010-2028. http://dx.doi.org/10.1016/j. engfracmech.2011.03.018.

[25] Nourpanah N, Taheri F. A numerical study on the crack tip constrain of pipelines subject to extreme plastic bending. Engineering Fracture Mechanics. 2011;78(6):1201-1217. http:// dx.doi.org/10.1016/j.engfracmech.2010.11.021.

[26] Zhang YM, Xiao ZM, Zhang WG. On 3-D crack problems in offshore pipeline with large plastic deformation. Theoretical and Applied Fracture Mechanics. 2013;67-68:22-28. http:// dx.doi.org/10.1016/j.tafmec.2014.01.001.

[27] Zhang YM, Yi DK, Xiao ZM, Huang ZH, Kumar SB. Elastic-plastic fracture analysis for pipeline girth welds with 3D semi-elliptical surface cracks subjected to large plastic bending. International 
Journal of Pressure Vessels and Piping. 2013;105-106:90-102. http://dx.doi.org/10.1016/j.ijpvp.2013.03.009.

[28] Kittel J, Ropital F, Pellier J. Effect of membrane thickness on hydrogen permeation in steels during wet hydrogen sulfide exposure. Corrosion. 2008;64(10):788-799. http://dx.doi. org/10.5006/1.3278446.

[29] Olden V, Alvaro A, Akselsen OM. Hydrogen diffusion and hydrogen influenced critical stress intensity in an API X70 pipelines steel welded joint - Experiments and FE simulations. International Journal of Hydrogen Energy. 2012;37(15):11474-11486. http:// dx.doi.org/10.1016/j.ijhydene.2012.05.005.

[30] Alvaro A, Olden V, Akselsen OM. 3D cohesive modelling of hydrogen embrittlement on the heat affected zone of an X70 pipeline steel - Part II. International Journal of Hydrogen Energy. 2014;39(7):3528-3541. http://dx.doi.org/10.1016/j. ijhydene.2013.12.097.

[31] Traidia A, Alfano M, Lubineau G, Duval S, Sherik A. An effective finite element model for the prediction of hydrogen induced cracking in steel pipelines. International Journal of Hydrogen Energy. 2012;37(21):16214-16230. http://dx.doi.org/10.1016/j. ijhydene.2012.08.046.

[32] American Society for Testing and Materials. ASTM E8-01: standard test methods for tension testing of metallic materials. West Conshohocken: ASTM; 2001.
[33] Ramirez JA, Gonzalez JL. Hydrogen induced cracking of welds in steel pipelines, design and analysis of pressure vessels and piping: implementation of ASME B31 - fatigue, ASME section VIII, and buckling analyses, PVP2003-2182. New York: ASME; 2003.

[34] Gonzalez JL, Hallen JM. Mecánica de fractura en ductos de recolección y transporte de hidrocarburos. 3 Congreso de Ductos PEMEX; 1998 Diciembre 7-9; México DF. México; 1998. 183-191.

[35] Ansys Inc. Introduction to ANSY for Release 8.0. Canonsburg: ANSYS; 2003.

[36] Ansys Inc. Release ANSYS 8.0 documentation: element reference - part I: element library. Canonsburg: ANSYS; 2003.

[37] Madeci E, Guven I. The finite element method and applications in engineering using Ansys. Springer; 2006.

[38] Meyers MA, Chawla KK. Mechanical behavior of materials. Cambridge: Prentice Hall; 1999.

[39] Dowling NE. Mechanical behavior of materials, engineering methods for deformation, fracture, and fatigue. 2nd Edition. Prentice Hall; 1999.

[40] The American Society of Mechanical Engineers. API 579-1/ ASME FFS-1: fitness-for-service. New York: ASME; 2007. 